\title{
Response of cerebrospinal fluid pressure to hyperbaric oxygenation ${ }^{1}$
}

\author{
T. HAYAKAWA, N. KANAI, R. KURODA, R. YAMADA, AND H. MOGAMI \\ From the Department of Neurosurgery, Osaka University Medical School, Osaka, Japan
}

SUMMARY The response of cerebrospinal fluid pressure (CSFP) to hyperbaric oxygenation (OHP) was investigated in 13 patients with acute cerebral damage and in dogs with or without experimentallyproduced cerebral damage. To elucidate the mechanism of the CSFP response, continuous measure- $-_{-\infty}^{\infty}$ ments of carotid blood flow, arterial blood pressure, central venous pressure, and superior sagittal $\vec{\circ}$ sinus pressure and CSFP were made before, during and after OHP. There was considerable varia- $\overrightarrow{\vec{\omega}}$ tion in the response of CSFP to OHP in the patients, but three main patterns emerged; type I (nine cases), CSFP decreased at the beginning and rose again at the end of OHP, type II (two cases), $\overline{\mathrm{B}}$ CSFP fell with OHP and remained significantly lower than pretreatment level after it, and type III (two cases), CSFP showed little change with OHP. An animal without cerebral damage com- + monly showed a type I response of CSFP to OHP; the changes of CSFP at the beginning and entar of OHP are mainly due to the changes of the cerebral blood flow. There may be two differefto actions of OHP on cerebral oedema, one decreasing cerebral oedema and another (mainf을 affecting the normal brain) producing cerebral oedema. Information obtained from the responseof CSFP to OHP may be useful in judging the severity and pathophysiological state of cerebralo damage.

Attention has been directed recently to hyperbaric oxygenation (OHP) for the treatment of various diseases (Barach, 1963; Boerema, Brummelkamp, and Meijne, 1964; Ledingham, 1965; Brown and Cox, 1966), and Sukoff, Hollin, and Jacobsen, 1967; and Sukoff, Hollin, Espinosa, and Jacobsen, 1968, demonstrated that hyperbaric oxygenation decreased the mortality in animals with experimentally produced cerebral oedema and caused a consistent drop in cerebrospinal fluid pressure (CSFP).

The purpose of the present paper is to study the response of cerebrospinal fluid pressure to hyperbaric oxygenation in normal and pathological conditions and to estimate its mechanism.

\section{METHODS}

Investigations were conducted under the following headings: Clinical study. Changes of cerebrospinal fluid pressure (CSFP) by OHP in patients with acute cerebral damage. Experimental study. Responses of CSFP, carotid

${ }^{1}$ Presented at the 27th Annual Meeting of the Japan Neurosurgical Society, Tokyo, 14 October 1968, at the third Annual Meeting of the Japanese Society of Hyperbaric Medicine, Tokyo, 31 October 1968, and at the 4th Annual Meeting of the Japanese Society of Hyperbaric Medicine, Hokkaido, 1 September 1969. blood flow (CBF), arterial blood pressure (BP), central venous pressure (CVP), and superior sagittal sinus. pressure (SSVP) to OHP in dogs with or without experimental cerebral damage.

CLINICAL STUDY CSFP changes by OHP were investi-ฏ gated in 13 patients suffering from acute cerebral damage. Nine patients had sustained closed head injury and were in the acute post-traumatic period. Four patients had hado craniotomy for brain tumour and were in the immediate 3 postoperative state. All patients had severe neurological disorders and were comatose. Six patients were breathing? spontaneously as there were no associated respiratorydisorders, but in seven patients intermittent positive pressure ventilation had been established.

The patients were treated in a hyperbaric chamber 3 designed to operate at high pressure and large enough to accommodate the patient and attendant staff, essentialo monitoring and therapeutic equipment. OHP treatment 3 was given at a pressure of two atmospheres absolute응 (ATA) for one hour. Pure oxygen was administered continuously to the patient by non-rebreathing face masko or endotracheal tube. Compression was carried out at 0.1 to $0.2 \mathrm{~kg} / \mathrm{sq} . \mathrm{cm} / \mathrm{min}$ and decompression was carried out according to Meijne's new decompression schedule (Meijne, 1964).

CSFP was measured continuously with a water mano- 
meter connected to a catheter inserted into the lateral ventricle of the cerebrum via a burr hole in the frontal lobe. Physicians always accompanied the patient in the chamber, checked the vital and neurological signs, and collected arterial blood samples for measurement of oxygen and carbon dioxide gas tensions $\left(\mathrm{PaO}_{2}\right.$ and $\mathrm{PaCO}_{2}$ ) and $\mathrm{pH}$.

EXPERIMENTAL STUDY Forty-six mongrel dogs weighing between 12 to $20 \mathrm{~kg}$ were used. The animals were lightly anaesthetized with pentobarbitone sodium (Nembutal) and rendered flaccid by gallamine triethiodide throughout the period of observation. Ventilation was controlled with an Aika respirator R-50 breathing air or pure oxygen to maintain $\mathrm{Pa} \mathrm{CO}_{2}$ within $35 \pm 5 \mathrm{~mm} \mathrm{Hg}$ through a cuffed endotracheal tube.

To measure CSFP, an 18 gauge needle was inserted into the cisterna magna; to measure BP and CVP catheters were inserted through the femoral artery and vein to the abdominal aorta and inferior vena cava. For measurement of SSVP an $0.5 \mathrm{~mm}$ catheter was inserted so as not to interfere with blood passing into the superior sagittal sinus via a burr hole in the mid-occipital region. These needle and catheters were connected by means of hard plastic tubes to manometric transducers (Toyo Measuring Instrument Co. Ltd.: LPU-0.5) and recorded by a multipurpose polygraph system (Nihon Koden Co.: RM-150). Some of the recordings were made with mercury or water manometers. After the right common carotid artery was dissected free by an anterior midline cervical incision and all branches except the internal carotid artery were ligated, carotid blood flow was quantitatively determined by a square-wave electromagnetic flowmeter (Nihon Koden Co.: MF-5). The calibration was carried out whenever atmospheric pressure was changed. After the surgical procedures were completed, heparin was given intravenously $(2 \mathrm{mg} / \mathrm{kg})$.

OHP was administered at 3 ATA in a hyperbaric chamber for one hour. Compression was carried out at $0.1 \mathrm{~kg} / \mathrm{sq} . \mathrm{cm} / \mathrm{min}$ and decompression was carried out according to Meijne's new schedule (Meijne, 1964). When $\mathrm{PaCO}_{2}$ was over the range $35 \pm 5 \mathrm{~mm} \mathrm{Hg}$ or cerebrospinal fluid was bloody, the experiment was ceased and the data obtained were excluded.

Dogs were divided into two groups. The first group, consisting of 34 animals in which no cerebral damage was produced, was used to determine the normal physiological responses to OHP. The second group, composed of 12 animals in which some degree of experimental cerebral damage had been produced by means of an extradural balloon-compression technique, was used to determine the pathological responses to OHP.

\section{RESULTS}

CLINICAL STUDY CSFP changes produced by OHP in the patients with cerebral damage are illustrated graphically in Fig. 1. The response varied considerably from patient to patient, but three main patterns of response emerged. In the first group, CSFP fell with OHP after initial fluctuation caused by the beginning of compression, and reverted rapidly with decompression at the end of OHP. After the cessation of OHP, CSFP commonly showed a temporary rebound and considerably exceeded the pretreatment level. It can be seen (Fig. 1) that the marked decrease of CSFP by OHP may result in marked rebound of CSFP after OHP. Even during OHP, CSFP which had initially fallen by OHP was liable to increase gradually with passage of time, and this upward tendency of CSFP during OHP was more striking when OHP continued beyond about 30 minutes. In the second type of response, CSFP showed little rebound, and the CSFP after OHP was significantly lower than the pretreatment level. Finally, CSFP sometimes showed little response to OHP, and maintained a consistently low or high level during and after OHP. Of the 13 patients, nine showed the first, two the second, and two the third type of response.

When OHP produced a major change in CSFP, the neurological deficit of the patient was mild and the clinical improvement with OHP was remarkable. On the other hand, when CSFP was little changed by OHP, there was little clinical improvement and the patient commonly had extensive cerebral damage.

EXPERIMENTAL STUDY There was considerable variation in the response of CSFP to OHP in the normal dogs, but the characteristic findings were present to some degree in all these dogs. The percent changes of CBF, BP, SSVP, and CSFP by OHP are listed in the Table and the mean values are summarized graphically in Fig. 2. CBF fell rapidly with the beginning of OHP, continued to decrease during OHP, and tended to return to the pretreatment level with the end of OHP. However, CBF at 15 minutes after the cessation of OHP remained significantly below pretreatment level. BP showed little change except the small fluctuation at the time of compression and decompression. The response of CSFP to OHP varied considerably from animal to animal. However, in most cases, CSFP fell with the beginning of OHP and remained at a significantly low level during the first 20 to 30 minutes of OHP. It then had an upward tendency even during OHP. Furthermore, it showed a rapid increase on decompression and finally exceeded significantly the pretreatment level after OHP. The rebound of CSFP after OHP in the dogs was not so dramatic as in the clinical cases. CVP fell slightly at the beginning of OHP and became elevated after OHP, but the changes were only minimal. The change of SSVP produced by OHP resembled that of CVP, but as CSFP showed a gradual increase during OHP, SSVP also showed a slight upward tendency, and CSFP which showed 


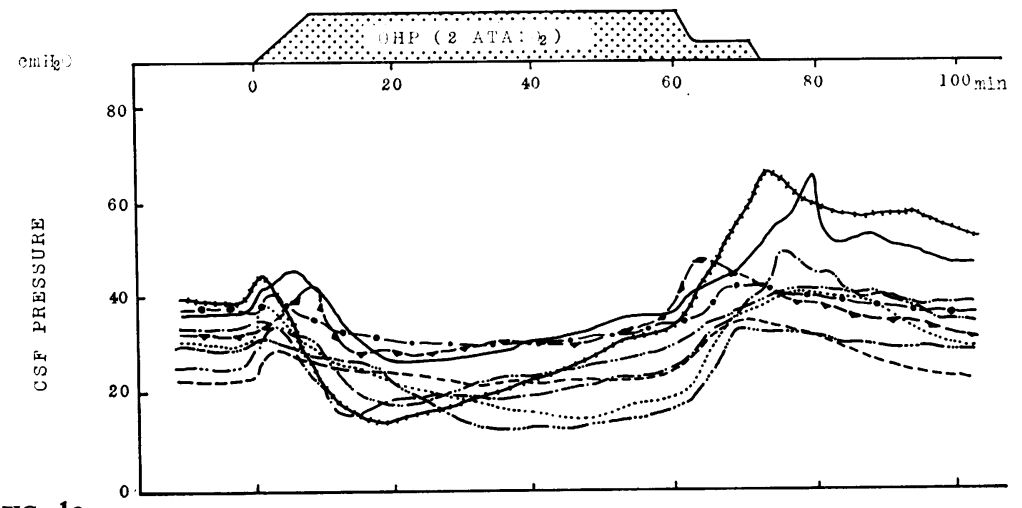

FIG. 1 .

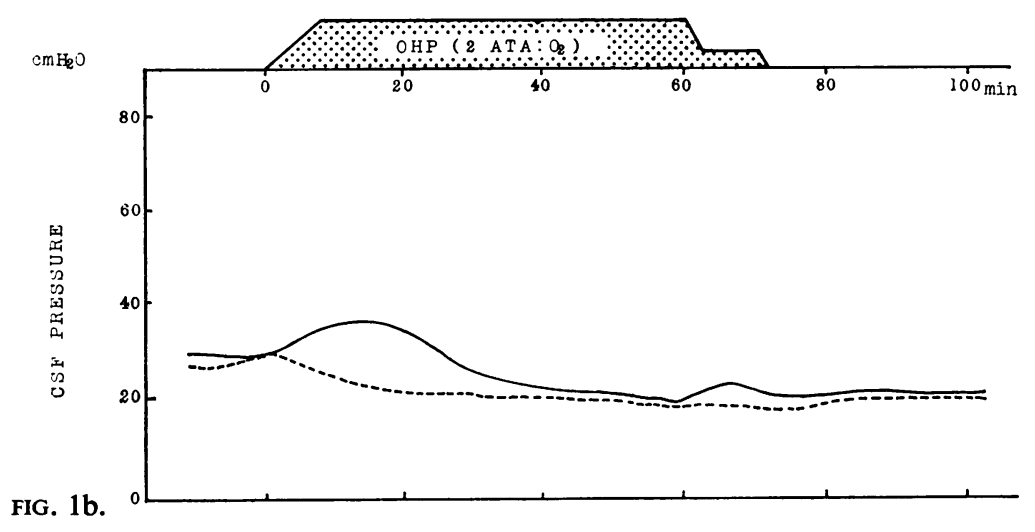

FIG. 1. Changes of cerebrospinal $\vec{\gtrless}$ fluid pressure (CSFP) produced by $O H P$ in 13 patients with acute cerebral damage. Each line represents a separate patient. (a) Down and up type (nine cases); CSFP decreased at the beginning of $O H P$ and reverted at the end of OHP. (b) Down type (two cases); CSFP decreased by OHP. (c) No response type (two cases), CSFP showed little change by $O H P$.

FIG. $1 \mathrm{~b}$

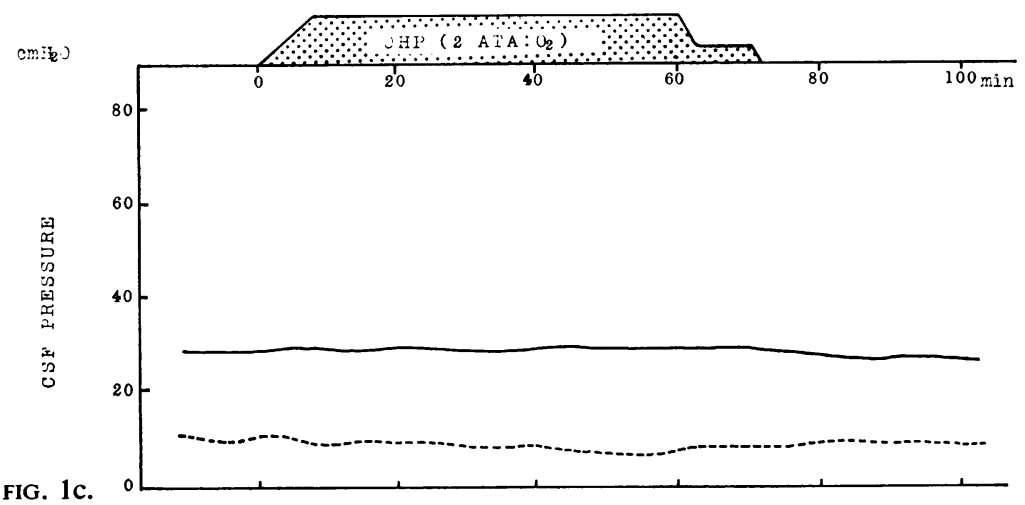

a marked rebound after OHP was accompanied by a moderate increase of SSVP. Figure 3 represents some of the polygraphs in which the changes of $\mathrm{CBF}$, $B P$, and CSFP in a dog without cerebral damage were demonstrated.
As compared with the response to OHP in dogs without cerebral damage, the CSFP response in N dogs with cerebral damage varied more remarkably. When cerebral compression with an extradural $N$ balloon was mild to moderate, a rise in CSFP was $\tilde{\omega}$ 
TABLE

PERCENT CHANGES OF BLOOD FLOW IN CAROTID ARTERY (CBF), ARTERIAL BLOOD PRESSURE (BP), CENTRAL VENOUS PRESSURE (CVP), VENOUS PRESSURE IN SAGITTAL SINUS (SSVP) AND CEREBROSPINAL FLUID PRESSURE (CSFP) PRODUCED BY OHP IN 34 NORMAL DOGS

\begin{tabular}{|c|c|c|c|c|c|}
\hline & \multirow{2}{*}{$\begin{array}{c}\text { Before } O H P \\
\mathrm{O}_{2}(15 \mathrm{~min})\end{array}$} & \multicolumn{3}{|c|}{ During $O H P(3 A T A)$} & \multirow{2}{*}{$\begin{array}{l}\text { After } O H P \\
\text { Air }(15 \mathrm{~min})\end{array}$} \\
\hline & & $\mathrm{O}_{2}(15 \mathrm{~min})$ & $\mathrm{O}_{2}(30 \mathrm{~min})$ & $\mathrm{O}_{2}(50 \mathrm{~min})$ & \\
\hline $\begin{array}{l}\text { CBF } \\
\text { BP } \\
\text { CVP } \\
\text { SSVP } \\
\text { CSFP }\end{array}$ & $\begin{array}{l}0.87 \pm 0.08 \\
0.97 \pm 0.04 \\
1.00 \pm 0.03 \\
0.96 \pm 0.04 \\
0.93 \pm 0.06\end{array}$ & $\begin{array}{l}0.78 \pm 0.17 \\
0.95 \pm 0.04 \\
0.90 \pm 0.10 \\
0.85 \pm 0.11 \\
0.74 \pm 0.19\end{array}$ & $\begin{array}{l}0.70 \pm 0.17 \\
0.97 \pm 0.06 \\
0.91 \pm 0 \cdot 10 \\
0.82 \pm 0 \cdot 10 \\
0.82 \pm 0.20\end{array}$ & $\begin{array}{l}0 \cdot 71 \pm 0 \cdot 14 \\
0.96 \pm 0.08 \\
0 \cdot 88 \pm 0.06 \\
0 \cdot 87 \pm 0.05 \\
0 \cdot 87 \pm 0.20\end{array}$ & $\begin{array}{l}0.92 \pm 0.14 \\
1.01 \pm 0.06 \\
1.03 \pm 0.14 \\
1.07 \pm 0.08 \\
1 \cdot 25 \pm 0.33\end{array}$ \\
\hline
\end{tabular}

All values are percentage changes.

followed by a fall in CBF. In such a case, CSFP generally responded to OHP as in normal animals, but the relative change was small and the rebound after OHP was minimal. When the compression so increased that the both pupils were dilated, CBF was extremely decreased, BP showed a rise or fall, and CSFP showed little or no response to OHP. Sudden evacuation of an extradural balloon after cerebral compression produced a marked increase in CBF followed by a rise, after a temporary fall, in CSFP. At this stage, CSFP showed a variable response to OHP; some showed a remarkable drop with a fall in CBF and some, no change with OHP.

\section{DISCUSSION}

Since the suggestion by Illingworth, Smith, Lawson, Ledingham, Sharp, and Griffiths (1961) and Boerema (1961) that oxygen under increased pressure could be beneficial in cardiac surgery, attention has been directed to hyperbaric oxygenation for the treatment of various diseases. In a previous report we investigated the clinical application of hyperbaric oxygenation in the treatment of acute cerebral damage (Mogami, Hayakawa, Kanai, Kuroda, Yamada, Ikeda, Katsurada, and Sugimoto, 1969), but there have yet been few reports on the effect of OHP on head injuries (Fasano, De Nunno, Urciuoli,

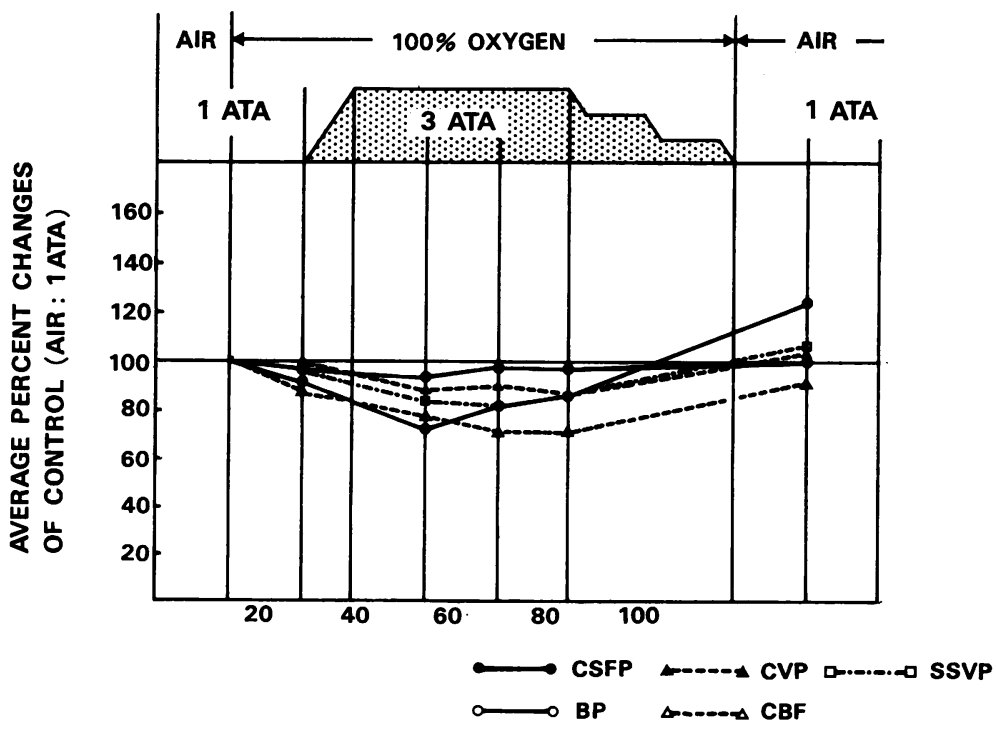

FIG. 2. Schematic representation of changes of cerebrospinal fluid pressure (CSFP), central venous pressure (CVP), venous pressure in sagittal sinus (SSVP), arterial blood pressure $(B P)$, and blood flow in carotid artery $(C B F)$ produced by $O H P$ in normal dogs. 


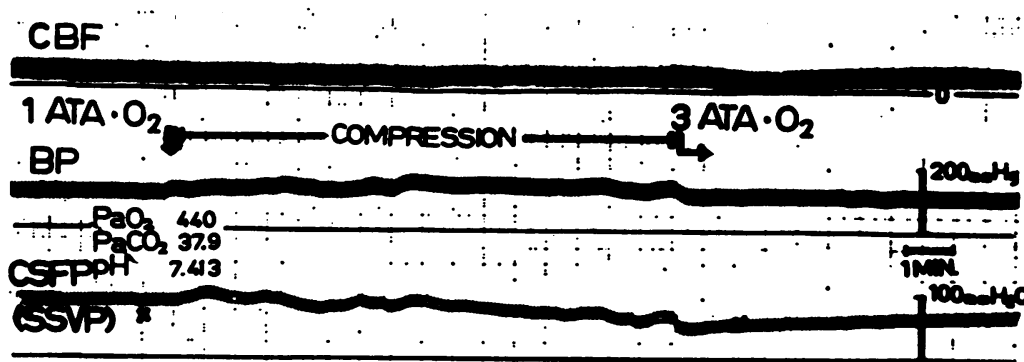

\section{A: AT THE BEGNMNG OF OP}
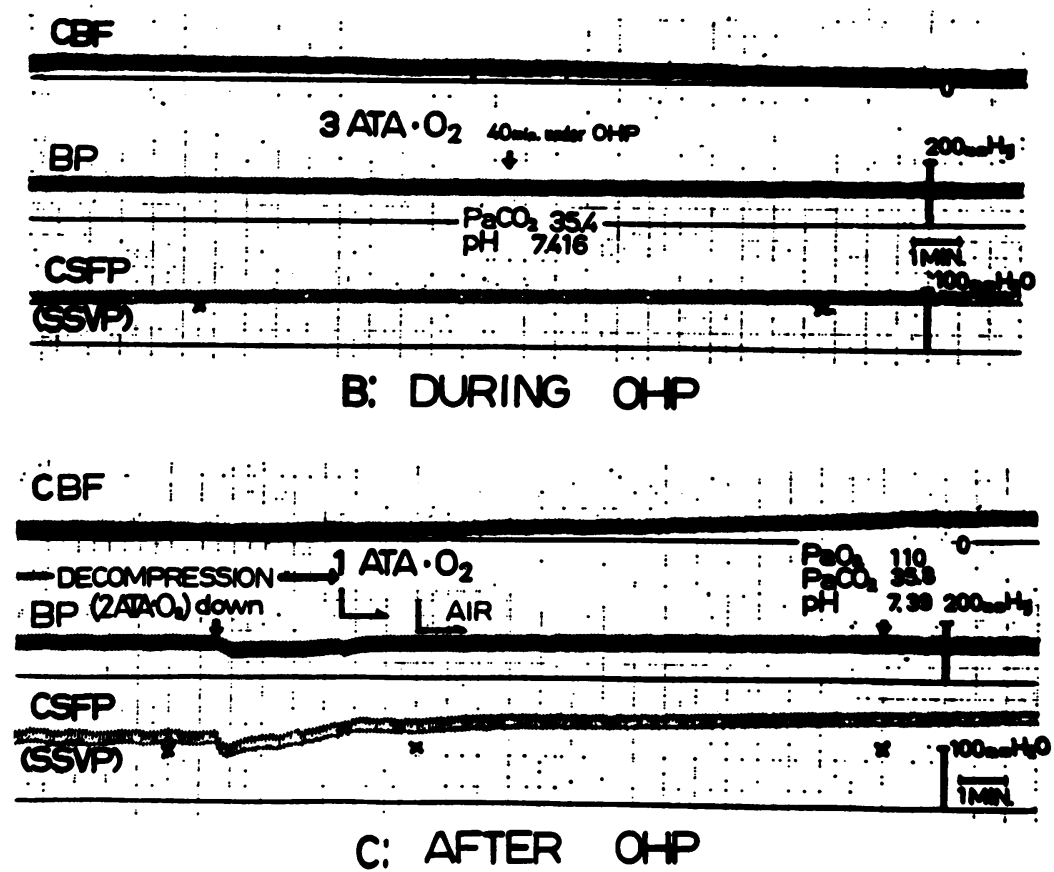

FIG. 3. Polygraphs showing changes of blood flow in carotid artery $(C B F)$, arterial blood pressure $(B P)$, and cerebrospinal fluid pressure (CSFP) with change of venous pressure in sagittal sinus (SSVP) produced by OHP in a normal dog of the series. A : at the beginning of $O H P, C B F$ shows a significant decrease followed by a fall in CSFP, and BP (and SSVP) are almost constant except during compression in $O H P$ chamber. $\mathrm{B}$ : during $O H P, C B F$ continues to decrease, BP (and SSVP) shows little change and CSFP has a tendency to increase slightly. C: after $O H P$, $C B F$ reverts to pretreatment level, BP changes little, and CSFP shows a considerable rebound.

and Lombard, 1964; Dunn and Connolly, 1966; Coe and Hayes, 1966; Sukoff et al., 1967; Sukoff et al., 1968), and cerebrovascular diseases (Ingvar and Lassen, 1965; Heyman, Saltzman, and Whalen, 1966; Saltzman, Anderson Jr., Whalen, Heyman, and Sieker, 1966) and little is known about the mechanism of its therapeutic effect. Extensive study $\frac{7}{0}$ on the effect of OHP on experimentally produced cerebral damage in dogs has been conducted by $N$ Sukoff et al. $(1967,1968)$ who demonstrated that $N$ cerebrospinal fluid pressure in dogs with cerebral oedema was reduced after OHP. 
Measurements of CSFP in cases of acute head injury have been reported and the value of such measurements has been discussed by many investigators (Cannon, 1901; Russell, 1932; White, Brooks, Goldthwait, and Adams, 1943; Lundberg, 1960; Lundberg, 'Troup, and Lorin, 1965; Langfitt and Kassell, 1966; Langfitt, Tannanbaum, and Kassell, 1966). It is well known that acute cerebral damage usually results in increased intracranial volume and is accompanied by elevated CSFP. Our observations in this series clearly demonstrate that there was a considerable variation in CSFP response to OHP in the patients with acute cerebral damage. The variation was thought to reflect differences in the underlying pathophysiological state of the brain.

Weed and McKibben (1919) modified the MonroKellie hypothesis and postulated that the cranial cavity is relatively fixed in volume and is completely filled by brain, cerebrospinal fluid, and blood. Variations in any one of the components may occur and compensation is afforded by alterations in the volumes of the remaining elements. A change in CSFP is observed only before equilibrium is achieved by redistribution among the components.

It is well established that OHP decreases cerebral blood flow by cerebral vasoconstriction (Lambertsen, Kough, Cooper, Emmel, Loeschcke, and Schmidt, 1953; Jacobson, Harper, and McDowall, 1963; Harper, Jacobson, and McDowall, 1965; Ledingham, McDowall, and Harper, 1966; Tindall, Wilkins, and Odom, 1966). Available evidence obtained from this experiment indicates that, in the physiological state, CSFP decreased with OHP and reverted with decompression, and that the changes were mainly due to a change in intracranial blood volume. There were significant decreases and increases in cerebral blood flow, but little change in arterial blood pressure and central venous pressure. There was no evidence of rapid change in cerebrospinal fluid volume.

Additional evidence obtained from the clinical and experimental data indicate that when OHP was maintained for a long time, CSFP, which had initially decreased, showed a tendency to rise, while BP and CVP showed little change and CBF continued to decrease. Data reported by us recently demonstrated that long-continued OHP increased the water content of the brain and altered its sodium distribution (Mogami, Hayakawa, Kuroda, Kanai, Yamada, Hori, Mukawa, Ikeda, Kobayashi, Murui, Taneda, and Jinnai, 1968). These results suggest that long-continued OHP may result in cerebral oedema

On the other hand, some investigators have indicated that OHP improves cerebral oedema (Dunn and Connolly, 1966; Sukoff et al., 1967;
Sukoff et al., 1968). Sukoff et al. (1967, 1968) suggested that OHP was accompanied by a large increase in available oxygen and the resulting cerebral vasoconstrictive action had a favourable effect on brain oedema caused by and accompanied by abnormal cerebral vasodilatation. The results obtained by Sukoff et al. $(1967,1968)$ indicating that CSFP in dogs with experimentally-produced cerebral oedema dropped after OHP, and the observation doing the present study that several dogs and two patients with acute cerebral damage had decreases in CSFP after OHP treatment support the view that OHP improves cerebral oedema in some instances. This has led to the concept that there may be two different actions of OHP in respect of cerebral oedema-namely, an action which improves cerebral oedema and an action which may actually produce cerebral oedema, and that the individual pathophysiological state of the brain will determine the action of OHP. If such were the case, it would help to explain our observations that there was considerable variation in the response of CSFP to OHP in patients and animals with cerebral damage.

The temporary rebound of CSFP after OHP may have been due to cerebrovascular congestion in addition to an increase of water content in the brain, for a marked elevation of CSFP was accompanied with a mild elevation of SSVP; the exact mechanism involved in this reaction is not completely clear.

In the present study, there were two patients and some dogs with extradural balloon compression which showed little CSFP response to OHP and they usually had severe cerebral damage. These results strongly suggest that when CSFP shows little response to OHP, the patient may have extensive cerebral damage, a seriously disturbed cerebral blood supply, loss of tonus of the cerebral blood vessels, and/or vasomotor paralysis.

It is of considerable practical significance that information obtained from the CSFP response to OHP may greatly facilitate the judgement of the severity and pathophysiological state of the cerebral damage and provide a quantitative estimation of the degree of cerebral vasomotor paralysis. Further studies into this problem would help the development of OHP treatment for cerebral damagefor example, in connection with compression and decompression schedules, treatment time, and suitable atmospheric pressure for the treatment of cerebral damage.

Grateful acknowledgement is made to Professor D. Jinnai for his guidance in this investigation. Thanks are tendered to Mr. S. Murakami for operation of the OHP chamber. 


\section{REFERENCES}

Barach, A. L. (1963). Hyperbaric oxygen and current medical uses of oxygen. N.Y.J. Med., 63, 2775-2782.

Boerema, I. (1961). An operating room with high atmospheric pressure. Surgery, 49, 291-298.

Boerema, I., Brummelkamp, W. H., and Meijne, N. G. (eds.) (1964). Clinical Application of Hyperbaric Oxygen. Proceedings of the First International Congress, Amsterdam, 1963. Elsevier: Amsterdam.

Brown, I. W., Jr., and Cox, B. G. (eds.) (1966). Proceedings of the Third International Conference on Hyperbaric Medicine, Duke University, Durham, North Carolina 1965, National Research Council Publication 1404. National Academy of Sciences: Washington, D.C.

Cannon, W. B. (1901). Cerebral pressure following trauma. Amer. J. Physiol., 6, 91-121.

Coe, J. E., and Hayes, T. M. (1966). Treatment of experimental brain injury by hyperbaric oxygenation. Preliminary report. Amer. Surg., 32, 493-495.

Dunn, J. E., II, and Connolly, J. M. (1966). Effects of hypobaric and hyperbaric oxygen on experimental brain injury. In Proceedings of the Third International Conference on Hyperbaric Medicine. Pp. 447-454. Edited by I. W. Brown, Jr. and B. G. Cox. National Research Council Publication 1404. National Academy of Sciences: Washington, D.C.

Fasano, V. A., De Nunno, T., Urciuoli, R., and Lombard, G. F. (1964). First observations on the use of oxygen under high atmospheric pressure for the treatment of traumatic coma. In Clinical Application of Hyperbaric Oxygen. Pp. 168-173. Edited by I. Bosrema, W. H. Brummelkamp, and N. G. Meijne. Elsevier: Amsterdam.

Harper, A. M., Jacobson, I., and McDowall, D. G. (1965). The effect of hyperbaric oxygen on the blood flow through the cerebral cortex. In Hyperbaric Oxygenation. Proceedings of the Second International Congress, Glasgow, 1964. Pp. 184-192. Edited by I. McA. Ledingham. Livingstone: Edinburgh.

Heyman, A., Saltzman, H. A., and Whalen, R. E. (1966). The use of hyperbaric oxygenation in the treatment of cerebral ischemia and infarction. Circulation, 33 (Suppl. 2), 20-27.

Illingworth, C. F. W., Smith, G., Lawson, D. D., Ledingham, I. McA., Sharp, G. R., and Griffiths, J. C. (1961). Surgical and physiological observations in an experimental pressure chamber. Brit. J. Surg., 49, 222-227.

Ingvar, D. H., and Lassen, N. A. (1965). Treatment of focal cerebral ischaemia with hyperbaric oxygen. Report of 4 cases. Acta neurol. scand., 41, 92-95.

Jacobson, I., Harper, A. M., and McDowall, G. D. (1963). The effects of oxygen under pressure on cerebral bloodflow and cerebral venous oxygen tension. Lancet, 2, 549.

Lambertsen, C. J., Kough, R. H., Cooper, D. Y., Emmel. G. L., Loeschcke, H. H., and Schmidt, C. F. (1953), Oxygen toxicity. Effects in man of oxygen inhalation at 1 and $3 \cdot 5$ atmospheres upon blood gas transport, cerebral circulation and cerebral metabolism. J. appl. Physiol., 5, 471-486.

Langfitt, T. W., Tannanbaum, H. M., and Kassell, N. F. (1966). The etiology of acute brain swelling following experimental head injury. J. Neurosurg., 24, 47-56.

Langfitt, T. W., and Kassell, N. F. (1966). Acute brain swelling in neurosurgical patients. J. Neurosurg., 24, 975-983.

Ledingham, I. McA. (ed.) (1965). Hyperbaric Oxygenation.
Proceedings of the Second International Congress, Glasgow 1964. Livingstone: Edinburgh.

Ledingham, I. McA., McDowall, D. G., and Harper, A. M. (1966). Cerebral cortical blood flow under hyperbaric conditions. In Proceedings of the Third International Conference on Hyperbaric medicine. Duke University, $\square$ Durham, North Carolina, 1965. Pp. 243-249. Edited by I. W. Brown, Jr. and B. G. Cox. National Research Council Publication 1404. National Academy of Sciences: Washington D.C.

Lundberg, N. (1960). Continuous recording and control $>$ of ventricular fluid pressure in neurosurgical practice. $\overrightarrow{\vec{F}}$ Acta psychiat. neurol. scand., 136 (Suppl 149), 1-193.

Lundberg, N., Troupp, H., and Lorin, H. (1965). Continuous $\bar{\sigma}$ recording of the ventricular-fluid pressure in patients with severe acute traumatic brain injury. J. Neurosurg., 22, 581-590.

Meijne, N. G. (1964). Compression and decompression with $\mathbb{D}$ their special aspects for hospital units. In Clinical Application of Hyperbaric Oxygen. Pp. 261-266. Edited by I. Boerema, W. H. Brummelkamp, and N. J. Meijne. Elsevier: Amsterdam.

Mogami, H., Hayakawa, T., Kuroda, R., Kanai, N., $\overrightarrow{\vec{\omega}}$ Yamada, R., Hori, M., Mukawa, J., Ikeda, T., Kobayashi, K., Murui, H., Taneda, M., and Jinnai, D. (1968). Effect of hyperbaric oxygenation on cerebral damage. Communication to the 27th Annual Meeting of the Japan Neurosurgical Society, Tokyo, October 14, 1968.

Mogami, H., Hayakawa, T., Kanai, N., Kuroda, R., Yamada, iv R., Ikeda, T., Katsurada, K., and Sugimoto, T. (1969) if Clinical application of hyperbaric oxygenation for trea\& $\bigcirc$ ment of acute cerebral damage. J. Neurosurg., 31, 636-64\$

Monro, A. (1783). Observations on the Structure and Fun tions of the Nel vous System. Creech: Edinburgh.

Russell, W. R. (1932). Cerebral involvement in head injur A study based on the examination of two hundred cases Brain, 55, 549-603.

Saltzman, H. A., Anderson, B., Jr., Whalen, R. E., Heymał A., and Sieker, H. O. (1966). Hyperbaric oxygen thera of acute cerebral vascular insufficiency. In Proceedings $\overrightarrow{\text { of }} v$ the Third International Conference on Hyperbaric Medicine, $\rightarrow$ Duke University, Durham, North Carolina, 1965. Pp. 440446. Edited by I. W. Brown, Jr. and B. G. Cox. National Research Council Publication 1404. National Academy of Sciences: Washington, D.C.

Sukoff, M. H., Hollin, S. A., and Jacobson, J. H., II. (1967). The protective effect of hyperbaric oxygenation in experimentally produced cerebral edema and compression. Surgery, 62, 40-46.

Sukoff, M. H., Hollin, S. A., Espinosa, O. E., and Jacobson, J. H., II. (1968). The protective effect of hyperbaric oxygenation in experimental cerebral edema. J. Neurosurg., 29, 236-241.

Tindall, G. T., Wilkins, R. H., and Odom, G. L. (1966). Effect of hyperbaric oxygenation on blood flow in the internal carotid artery of the baboon. In Proceedings of the Third International Conference on Hyperbaric Medicine, Duke University, Durham, North Carolina, 1965. Pp. 236242. Edited by I. W. Brown Jr. and B. G. Cox. National Research Council Publication 1404. National Academy of Sciences: Washington, D.C.

Weed, L. H., and McKibben, P. S. (1919). Experimental alteration of brain bulk. Amer. J. Physiol., 48, 531-558.

White, J. C., Brooks, J. R., Goldthwait, J. C., and Adams, $\frac{7}{2}$ R. D. (1943). Changes in brain volume and blood content after experimental concussion. Ann. Surg., 118, 619-634. 